East African Medical Journal Vol. 86 No. 8 August 2009

INTERMITTENT PRESUMPTIVE TREATMENT OF MALARIA TO PREVENT LOW BIRTH WEIGHT IN NEWBORNS IN A COHORT OF PREGNANT WOMEN FROM A MALARIA ENDEMIC AREA

D. N. Alusala, BSc, MSc, PhD, Research Scientist, Division of Malaria Control, Ministry of Public Health and Sanitation and B. B. A. Estambale, MBChB, MSc, DTM\&H, PhD, Director, Institute of Tropical and Infectious Diseases, University of Nairobi, P. O. Box 19676-00202, Nairobi, Kenya

Request for reprints to: Prof. B. B.A. Estambale, Institute of Tropical and Infectious Diseases, University of Nairobi, P.O. Box 19676 - 00202, Nairobi, Kenya

\title{
INTERMITTENT PRESUMPTIVE TREATMENT OF MALARIA TO PREVENT LOW BIRTH WEIGHT IN NEWBORNS IN A COHORT OF PREGNANT WOMEN FROM A MALARIA ENDEMIC AREA
}

\author{
D. N. ALUSALA and B. B. A. ESTAMBALE
}

\begin{abstract}
Objective: To determine and describe the patterns of low birth weight in newborns of a cohort of mothers given intermittent presumptive treatment (IPT) for malaria prevention in a malaria endemic area of Kenya.

Design: A longitudinal prospective cohort study.

Setting: Got Agulu Health Centre in Usigu Division, Bondo District, Nyanza Province. Subjects: Pregnant women of all parities attending antenatal care services. Only women who gave informed consent for themselves and their newborns afterbirth were eligible to participate in the study.

Results: Parity was highly predictive of birth weight in the study subjects. Primigravidae and secondigravidae had a significantly lower mean birth weight (2952g) than women of higher gravidity $(\mathbf{3 2 1 4} \mathrm{g}$ ) p-value $<\mathbf{0 . 0 0 0 1}$. Regardless of IPT administration, women who became positive for malaria infection at any point during pregnancy delivered $73.7 \%$ of the LBW infants. There was no significant difference in mean birth weights between primigravidae and multigravidae who had parasitaemia at baseline and at delivery (means $2906 \mathrm{~g}$ and $3062 \mathrm{~g}$ respectively, $\mathrm{p}=0.11$ ). However, there was a significant difference between the parasitaemia negative primigravidae and multigravidae at baseline and at delivery (means $2952 \mathrm{~g}$ and $3204 \mathrm{~g}$ respectively, $\mathrm{p}=0.006$ ). Infection with helminths did not have an effect on birth weight. Overall, low birth weight was observed in $9 \%$ of the newborns and was most commonly found in primigravidae and secondigravidae $(\mathbf{1 4 . 8 \%}$ and $13.1 \%$ respectively).

Conclusion: Although many factors have been known to play a role in the causation of low birth weight $(\mathrm{LBW}<2500 \mathrm{~g})$, parity status and malaria infection in malaria endemic areas still play a major role regardless of IPT administration.
\end{abstract}

\section{INTRODUCTION}

Malaria is a serious health problem in sub-Saharan Africa, where $80-90 \%$ of the world's cases occur annually. It is estimated that $1.8-2.7$ million children die annually of malaria, $90 \%$ of these coming from Africa(1).Disease transmission is endemic across most of sub-Saharan Africa with Plasmodium falciparum being the parasite responsible for the majority of infections and almost all the malaria associated complications.

Most affected are young children and pregnant women making the infection an important risk factor for morbidity and mortality in pregnancy (2) and being particularly dangerous in primigravidae (3). In areas of unstable transmission, the infection results in frequent malaria attacks, high parasite densities and anaemia, which lead to abortions and stillbirths $(4,5)$. On the other hand, in areas of stable and perennial transmission, pregnant women experience a high frequency and density of parasitaemia, but severe malaria related illnesses, are uncommon except anaemia. Fever or signs and symptoms suggestive of malaria are infrequently reported by infected women, and only $25 \%$ of such women have detectable parasitaemia, suggesting that perceived malaria among pregnant women is not a reliable predictor of current malaria infection (6). HIV infection has been shown to be associated with a significant increase in malaria infection in pregnant women of all parities (7), but there has been no similar association between HIV -seropositivity and severe anaemia although in pregnant women, HIV-seropositivity increases the risk of being anaemic (8) leading to low birth weights in newborns of the affected mothers.

Maternal malaria is associated with reduced birth weight. This is thought to be effected through 
placentalinfection, which leads to intrauterine growth retardation (IUGR) and pre-term labour (9). LBW is also a risk factor for neonatal and early infant mortality (10-12). Prevention of placental malaria, through administration of antimalarial chemoprophylaxis or intermittent presumptive treatment(IPT) to pregnant women in malaria endemic areas, has been shown to decrease the risk of delivery of infants with low birth weight (13-15).

Malaria in pregnancy is also associated with severe maternal anaemia (16). A study carried out in Kilifi District of coastal Kenya, an area with moderate malaria transmission, showed that women of all parities had substantially increased risk of developing severe anaemia in addition to delivering low birth weight babies (17). Previous investigations in subSaharan Africa have demonstrated that prevention of malaria during pregnancy isimportant, especially for the primigravidae $(6,18,19)$, and that an efficacious antimalarial regimen, which clears placental infection, will result in a reduction of the incidence of anaemia and LBW. Following the recognition that malaria is a major problem, the Ministry of Health of Kenya is actively involved in its control by promoting the use of insecticide treated bed-nets, indoor spraying and IPT in pregnancy. The malaria control strategy implies that all pregnant women should get sulphadoxine/ pyrimethamine (SP) during the second and third trimester. Based on the policy of IPT administration in pregnancy in malaria endemic areas of the country, a study was carried out to determine and describe the patterns of low birth weight in newborns of a cohort of mothers given IPT for malaria prevention in Bondo District of Nyanza Province, western Kenya.

\section{MATERIALS AND METHODS}

Study area: The study was conducted in Bondo District within Nyanza Province of Kenya (Figure 1). The District lies on the northern shores of Lake Victoria bordered by Siaya, Busia and Kisumu Districts to the north, west and east respectively and covers a total area of $1,977 \mathrm{~km}^{2}$ with only $972 \mathrm{~km}^{2}$ making up the land area while the rest is water surface of Lake Victoria. The District experiences intense perennial malaria transmission with an entomological inoculation rate (EIR) of between 60 - 200 bites per year. 0.25/1000 clinical attacks occur every year in all age groups but more so in those between the ages of 8 to 17 years. Theintense transmission of malaria places the burden of malaria disease on the very young children and pregnant women.

Study population: Pregnant women at a gestational age of between 14 - 24 weeks were identified for recruitment. Gestation age was calculated based on the first day of the last menstrual period for those who could remember, while for those unable to recall, an assessment by the midwife in the ANC clinic was done. At enrolment and on subsequent follow up, a standardised questionnaire was used to collect the relevant bio-information which included age, weight, height, education background, socioeconomic status, parity status and the dates of the last menstrual period. The recruited women were monitored monthly for up to 36 weeks gestation and then weekly until delivery. As part of ANC, physical and clinical examinations were performed and IPT given at the beginning of the second and third trimesters. A stool sample was collected at enrolment and examined for helminth infections. Those found infected were treated with albendazole as per the $\mathrm{MOH}$ policy. Because of the likelihood of home delivery and therefore loss of vital birth parameters, the recruited women were requested to report at 37 weeks of gestation for admission until hospital delivery. Those declining admission continued with weekly visits until delivery but requested to report immediately at the onset of labour or within hours of delivery.

If delivery was within the hospital, infant birth weight and placental weight were immediately recorded and Dubowitz score of infant maturity assessed. For those delivering outside the hospital and reporting within three hours, only birth weight and placental weight were recorded. Blood specimens were taken from both mother and infant, the placenta and the umbilical cord.

Sickling test: A sickling test was done as a screening test for sickle cell trait. An equal volume of sodium meta- bisulphate was added to a freshly obtained drop of blood on a blood slide. The two were mixed well, a cover slip added and sealed with candle wax. The slide was then left at room temperature for 30 minutes after which the slide was examined for sickle cells under the microscope. Due to lack of equipment $\mathrm{Hb}$ electrophoresis was not performed.

Exclusion/inclusion criteria: Mothers who declined to be involved in the study were excluded but routinely followed up at the ANC. All known cases of chronic diseases such as diabetes, hypertension, malignancies, HIV / AIDS or any other disease likely to affect the progress of a normal pregnancy were also excluded. Mothers with twin pregnancies were included and followed up but excluded from the analysis since multiple pregnancies are well documented as causes of low birth weight and prematurity.

Laboratory investigations: Thin and thick blood films for malaria parasites were done and stained in $4 \%$ Giemsa stain. Malaria parasites were counted against 200 leucocytes. A blood slide was considered negative if no parasites were found after counting 500 leucocytes. Parasite density / $\mu \mathrm{L}$ was calculated on the basis of individual white blood cell count. Blood from the 
umbilical cord was collected for completehaemogram and malaria parasite smears. The maternal side of the placenta was cleaned with gauze and a deep cut made using a surgical blade. Thick and thin blood films were made on glass slides and stained in $4 \%$ Giemsa stain. Haemoglobin estimation was done using a portable haemoglobinometer (Haemocue ${ }^{\circledR} \mathrm{AB}$, Angelhom, Sweden), during normal monthly ANC visits and as part of a haemogram at recruitment, at the beginning of third trimester and at delivery. Stool samples were processed using the KATO- KATZ technique for the intensity of infection.

Ethical consideration: Pregnant women were only included if they fulfilled the inclusion criteria and had signed an informed consent form, following a detailed explanation in the local language about the study and itsimplications. The study was approved by the Kenya Medical Research Institute (KEMRl) Ethical Review Committee and the Danish Central Ethical Committee. The project was part of a collaborative multidisciplinary study between the Kenyan and Danish scientists.

Statistical analysis: Data analysis was done using SPSS version 10. Malaria parasitaemia was $\log _{10}$ $(x+1)$ transformed. Intestinal helminth eggs were similarly log transformed before analysis. Means were compared using Analysis of Variance (ANOVA). Logistic Regression was used to determine predictors of birth weight. Prematurity was defined as a gestational age at birth of less than 37 weeks and IUGR as a birth weight of $<2500 \mathrm{~g}$ among babies with a gestational age $\geq 37$ weeks (20). $\mathrm{P}<0.05$ was considered significant.

\section{RESULTS}

Eight hundred and forty two women were recruited into the study. Of these, $692(82.2 \%)$ received two doses of SP. Data on birth weight was available for $78.9 \%$ (546/692), twin deliveries occurred in 1.2\% $(8 / 692)$ of cases and abortion / stillbirths occurred in $2.6 \%$ (18 / 692). Birth weight was not available for 120 babies as a result of mothers refusing to have their babies weighed, defaulting or migrating out of the study area. Data was also available from $658(95.1 \%)$ women for malaria at baseline, from $580(83.8 \%)$ at midterm and from $537(77.6 \%)$ at delivery. Placenta was examined for malaria in $490(70.8 \%)$ women and $473(86.6 \%)$ infants cord blood was examined for malaria. Table 1 shows the characteristics of the study population.

Malaria parasite prevalence: At baseline (between 1424 weeks of gestation), maternal malaria parasite prevalence was $44.5 \%$ (293/658), while at delivery it was $27.2 \%$ (146/537). The placenta parasite prevalence was $21.4 \%$ (105/490) and umbilical cord prevalence was found in $3.0 \%(14 / 473)$.

Birth weight: Table 2 shows the overall mean birth weight as $3107 \mathrm{~g}(95 \%$ CI 3067, 3147), and the overall prevalence of LBW babies was 9\% (49/578). Primigravidae delivered babies with the lowest mean birth weight of $2920 \mathrm{~g}(95 \%$ CI 2837,3003$)$ and had the highest frequency of LBW babies (14.8\%) than women with more than one pregnancy. Mean birth weight increased with increasing gravidity $(\mathrm{P}=0.0001)$.

Figure 1

Bondo district administrative boundaries

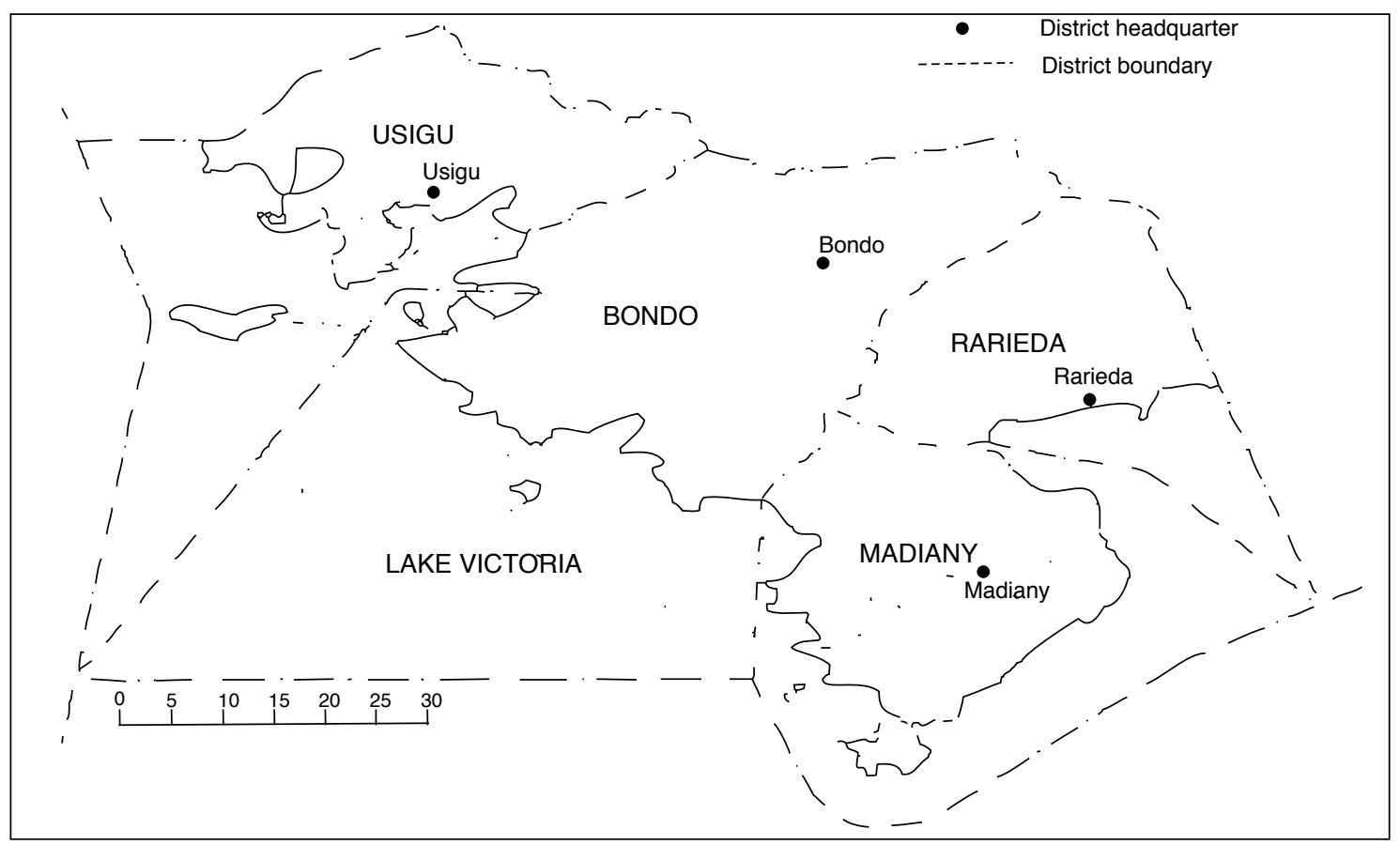


Table 1

Baseline characteristics of the study population

\begin{tabular}{|c|c|c|c|c|c|c|}
\hline Parameter & $\begin{array}{l}\text { All women } \\
(\mathrm{n}=842)\end{array}$ & $\begin{array}{l}\text { Gravida } 1 \\
(\mathrm{n}=177)\end{array}$ & $\begin{array}{l}\text { Gravida } 2 \\
(\mathrm{n}=204)\end{array}$ & $\begin{array}{l}\text { Gravida } 3 \\
(\mathrm{n}=134)\end{array}$ & $\begin{array}{l}\text { Gravida } 4 \\
(\mathrm{n}=97)\end{array}$ & $\begin{array}{l}\text { Gravida } \geq 5 \\
(\mathrm{n}=225)\end{array}$ \\
\hline $\begin{array}{l}\text { Mean gestational age } \\
\text { at baseline }(95 \% \mathrm{CI})\end{array}$ & $\begin{array}{l}17.5 \\
(17.3,17.7)\end{array}$ & $\begin{array}{l}18.3 \\
(17.8,18.8)\end{array}$ & $\begin{array}{l}17.2 \\
(16.8,17.6)\end{array}$ & $\begin{array}{l}17.6 \\
(17.1,18.2)\end{array}$ & $\begin{array}{l}16.9 \\
(16.3,17.4)\end{array}$ & $\begin{array}{l}17.3 \\
(19.9,17.7)\end{array}$ \\
\hline Mean age in years (range) & $\begin{array}{l}24.3 \\
(14-46)\end{array}$ & $\begin{array}{l}18.4 \\
(15,36)\end{array}$ & $\begin{array}{l}20.9 \\
(14,33)\end{array}$ & $\begin{array}{l}24.0 \\
(17,37)\end{array}$ & $\begin{array}{l}27.1 \\
(19,38)\end{array}$ & $\begin{array}{l}31.3 \\
(17,46)\end{array}$ \\
\hline Mean height in $\mathrm{cm}(95 \% \mathrm{CI})$ & $\begin{array}{l}162.5 \\
(162,162.9)\end{array}$ & $\begin{array}{l}161.8 \\
(160.9,162.7)\end{array}$ & $\begin{array}{l}162.7 \\
(161.8,163.5)\end{array}$ & $\begin{array}{l}161.7 \\
(160.6,162.7)\end{array}$ & $\begin{array}{l}162.5 \\
(161.2,163.8)\end{array}$ & $\begin{array}{l}163.3 \\
(162.1,164.5)\end{array}$ \\
\hline Mean weight in $\mathrm{kg}(95 \% \mathrm{CI})$ & $\begin{array}{l}58.1 \\
(57.6,58.6)\end{array}$ & $\begin{array}{l}58.0 \\
(57.0,59.0)\end{array}$ & $\begin{array}{l}56.9 \\
(56.0,57.8)\end{array}$ & $\begin{array}{l}57.1 \\
(55.9,58.3)\end{array}$ & $\begin{array}{l}57.9 \\
(56.2,59.7)\end{array}$ & $\begin{array}{l}60.0 \\
(59.0,61.1)\end{array}$ \\
\hline Positive sickling test $(\%)$ & 12.6 & 10.7 & 13.1 & 12.9 & 17.4 & 10.4 \\
\hline Bed net use $(\%)$ & 26.0 & 17.5 & 26.5 & 31.3 & 20.6 & 31.3 \\
\hline \multicolumn{7}{|l|}{ Occupation (\%) } \\
\hline Housewife & 50.5 & 59.9 & 57.8 & 53.0 & 50.5 & 35.0 \\
\hline Small scale businesses & 28.5 & 13.0 & 26.0 & 29.9 & 37.1 & 39.6 \\
\hline Farmer & 10.8 & 4.5 & 5.9 & 14.2 & 9.3 & 18.7 \\
\hline Formal employment & 3.9 & 2.9 & 2.0 & 2.8 & 2.1 & 6.7 \\
\hline Unknown & 6.4 & 20.3 & 8.3 & & 1.0 & \\
\hline \multicolumn{7}{|l|}{ Marital status (\%) } \\
\hline Married & 83.1 & 61 & 83.8 & 95.5 & 91.8 & 88.4 \\
\hline Single & 12.0 & 39.0 & 13.2 & 0.0 & 1.0 & 1.8 \\
\hline Widowed & 4.4 & 0.0 & 2.0 & 4.5 & 6.2 & 9.3 \\
\hline Separated & 0.2 & 0.0 & 0.5 & 0.0 & 0.0 & 0.4 \\
\hline Unknown & & & & 1.0 & & \\
\hline \multicolumn{7}{|l|}{ Level of education (\%) } \\
\hline None & 5.0 & 3.4 & 1.5 & 1.5 & 8.2 & 9.3 \\
\hline Primary & 77.8 & 84.7 & 80.6 & 80.6 & 77.3 & 72.9 \\
\hline Secondary & 15.5 & 10.7 & 17.2 & 17.2 & 9.3 & 15.1 \\
\hline College/University & 0.2 & 0.0 & 0.7 & 0.7 & 1.0 & 0.0 \\
\hline Unknown & 1.5 & 0.6 & & & 4.1 & 2.7 \\
\hline
\end{tabular}

Table 2

Mean birth weight and proportion with low birth weight in relation to gravidity

\begin{tabular}{lllll}
\hline Gravidity & Birth weight $(\mathrm{g})$ & $(95 \% \mathrm{CI})$ & $\begin{array}{l}\text { Proportion with } \\
\text { LBW(\%) }\end{array}$ & $\begin{array}{l}(95 \% \mathrm{CI}) \\
\end{array}$ \\
\hline All $\left(\mathrm{n}=578^{*}\right)$ & 3107 & $(3067,3147)$ & 9.0 & $(5,13)$ \\
$1(\mathrm{n}=122)$ & 2920 & $(2837,3003)$ & 14.8 & $(12.3,18.9)$ \\
$2(\mathrm{n}=129)$ & 2984 & $(2902,3066)$ & 13.1 & $(10.1,16.1)$ \\
$3(\mathrm{n}=96)$ & 3155 & $(3071,3239)$ & 4.5 & $(2.2,6.2)$ \\
$4(\mathrm{n}=66)$ & 3216 & $(3099,3333)$ & 6.5 & $(3.1,9.1)$ \\
$\geq 5(\mathrm{n}=163)$ & 3271 & $(3201,3340)$ & 5.1 & $(4.1,8.1)$
\end{tabular}

${ }^{*}$ Gravidity status was missing for two women although all other data was available. The data was included in the analysis for all women but excluded for individual gravidity groups 
Birth weight and malaria parasitaemia: Table 3 shows that being parasitaemic during pregnancy resulted in babies with low birth weights. Women who were parasitaemic at baseline had babies with a mean birth weight of $89 \mathrm{~g}$ lower than those who were aparasitaemic at baseline $(\mathrm{P}=0.026)$. Women who were parasitaemic at delivery gave birth to babies with a mean birth weight of $85 \mathrm{~g}$ lower than those who were a parasitaemic at delivery $(\mathrm{P}=0.06)$. Women who had infected placentas delivered babies with a mean birth weight of $152 \mathrm{~g}$ lower than those who had uninfected placentas $(\mathrm{P}=0.003)$. Women with parasitaemia at any point during pregnancy delivered $73.7 \%$ of the LBW infants. Being parasitaemic at baseline was important, as $86 \%$ of LBW infants occurred among these women.

Table 4 compares mean birth weights of primigravidae and multigravidae in relation to maternal malaria status. From the Table it is seen that malaria infection playsa major role in determining birth weight in primigravidae. Infection in primigravidae at any point in time resulted in smaller babies, unlike the multigravidae, who were only affected if the infection was present at both the enrolment and at delivery. The difference in birth weight between the aparasitaemic primigravidae and the aparasitaemic multigravidae was significant $(\mathrm{P}=0.006)$.

Birth weight and maternal $\mathrm{Hb}$ status: A maternal $\mathrm{Hb}$ concentration of $<105 \mathrm{~g} / \mathrm{L}$ at baseline was found in $35.6 \%$ of the women. These women delivered babies with a mean birth weight of 3002g (95\% CI 2963, 3041) as compared to those with a Hb concentration of $\geq 105 \mathrm{~g} / \mathrm{L}$ who had a mean birth weight of $3167 \mathrm{~g}$ (95\% CI 3127, 3207, p<0.0001) (Table 5). Women with an $\mathrm{Hb}$ of $<105 \mathrm{~g} / \mathrm{L}$ at delivery had babies with a mean birth weight of $3063 \mathrm{~g}(95 \%$ CI 3020, 3106) as compared to women with a $\mathrm{Hb}$ of $\geq 105 \mathrm{~g} / \mathrm{L}$ who had babies with a mean birth weight of $3149 \mathrm{~g}(95 \%$ CI 3109, 3189) $(\mathrm{P}=0.02)$.

Table 3

Mean birth weight and maternal malaria status during pregnancy

\begin{tabular}{llll}
\hline Malaria parasite status & Birth weight $(\mathrm{g})$ & $95 \%$ CI & P-value \\
\hline Aparasitaemic at baseline $(\mathrm{n}=384)$ & 3153 & $(3124,3178)$ & 0.026 \\
Parasitaemic at baseline $(\mathrm{n}=162)$ & 3062 & $(3033,3091)$ & \\
Aparasitaemic at delivery $(\mathrm{n}=400)$ & 3134 & $(3111,3157)$ & 0.06 \\
Parasitaemic at delivery $(\mathrm{n}=146)$ & 3049 & $(3011,3089)$ & \\
Aparasitaemic placentas $(\mathrm{n}=441)$ & 3152 & $(3128,3176)$ & 0.003 \\
Parasitaemic placentas $(\mathrm{n}=105)$ & 3000 & $(2957,3042)$ & \\
\hline
\end{tabular}

Table 4

Mean birth weight in relation to maternal malaria infection status and gravidity ${ }^{1}$

\begin{tabular}{llllc}
\hline Parameter & All & Primigravidae & Multigravidae $(\geq 2)$ & P-value \\
\hline Parasitaemic at baseline & 3015 & 2906 & 3062 & \\
and delivery & $(2921,3109)$ & $(2720,3093)$ & $(2954,3170)$ & 0.11 \\
Aparasitaemic at baseline & 3175 & 2952 & 3204 & \\
and delivery & $(3118,3232)$ & $(2789,3116)$ & $(3145,3264)$ & 0.006 \\
Parasitaemic at baseline, & 3073 & 2939 & 3167 & 0.0001 \\
aparasitaemic at delivery & $(2994,3152)$ & $(2711,2968)$ & $(3075,3259)$ & \\
Aparasitaemic at baseline & 3122 & 2882 & 3204 & 0.043 \\
parasitaemic at delivery & $(2983,3261)$ & $(2538,3227)$ & $(3057,3352)$ & \\
\hline
\end{tabular}

${ }^{195 \%}$ confidence interval in parentheses 
Table 5

Maternal haemoglobin concentration at baseline and delivery in relation to mean birth weight

\begin{tabular}{lll}
\hline Mean $\mathrm{Hb}$ concentration & Mean birth weight & P-value \\
\hline $\begin{array}{l}\text { Baseline } \\
\mathrm{Hb}<105 \mathrm{~g} / \mathrm{L}\end{array}$ & $3002 \mathrm{~g}(95 \%$ CI 2963, 3041) & \\
$\mathrm{Hb}>105 \mathrm{~g} / \mathrm{L}$ & $3167 \mathrm{~g}(95 \%$ Cl 3127, 3207) & $\mathrm{p}<0.0001$ \\
$\begin{array}{l}\text { Delivery } \\
\mathrm{H}<105 \mathrm{~g} / \mathrm{L}\end{array}$ & $3063 \mathrm{~g}(95 \%$ CI 3020, 3106) & \\
$\mathrm{Hb}>105 \mathrm{~g} / \mathrm{L}$ & $3149 \mathrm{~g}(95 \%$ CI 3109, 3189) & $\mathrm{p}=0.02$ \\
\hline
\end{tabular}

Birth weight and intestinal worms: Infant birth weight (at delivery) was compared to intestinal helminth infection (at recruitment) only in women followed up until they delivered $(n=546)$. Table 6 shows the prevalences of intestinal helminths infection at recruitment and the mean birth weight differences between the infected and non-infected. Hookworm was prevalent in 49.4\%, Ascaris lumbricoides in 14.9\%, Trichuris trichiura in $23.3 \%$ and Schistosoma mansoni in $62 \%$. All the parasites except S. mansoni were treated with albendazole in the second trimester, while $S$. mansoni was treated with praziquantel after delivery. Comparative analysis in birth weight was done between those who had been infected with these parasites and those who had no infection. The results showed that except for hookworm infection, there was a reduction in mean birth weights of babies born to mothers infected compared to those not infected although the differences were not statistically significant. Those infected with $T$. trichiura had a lower mean birth weight of $43 \mathrm{~g}$ compared to noninfected $(\mathrm{P}=0.35)$ A. lumbricoides had a lower mean birth weight of $21 \mathrm{~g}$ compared to non-infected $(\mathrm{P}=0.68)$ and $S$. mansoni had a lower mean birth weight of $26 \mathrm{~g}$ compared to non-infected $(\mathrm{P}=0.91)$. Contrary to expectations, those with hookworm infection had a mean birth weight of $45 \mathrm{~g}$ higher than the non-infected, which again was not significant $(\mathrm{P}=0.25)$. Results for multiple parasitic infections were not significantly different and are therefore not reported.

Table 6

Mean birth weight difference between the uninfected women and the infected in relation to intestinal worm infection $(n=546)$

\begin{tabular}{lllll}
\hline $\begin{array}{l}\text { Intestinal worm } \\
\text { infection }\end{array}$ & Prevalence & Intensity ${ }^{1}$ & $\begin{array}{l}\text { Birth weight } \\
\text { difference }(\mathrm{g})^{2}\end{array}$ & P-value \\
\hline Hookworm & $49.4 \%$ & $11(10,12)$ & 45 & 0.25 \\
Schistosoma mansoni & $62 \%$ & $16(15,17)$ & 26 & 0.91 \\
Ascaris lumbricoides & $14.9 \%$ & $3(2,4)$ & 21 & 0.68 \\
Trichuris trichiura & $23.3 \%$ & $2(2,3)$ & 43 & 0.35 \\
\hline
\end{tabular}

${ }^{1}$ Geometric mean intensity and (95\% CI)

${ }^{2}$ Birth weight difference between the infected women and the uninfected 
Overall prediction of birth weight: In order to determine the patterns of birth weight in the study population, a multiple logistic regression analysis was done (Table 7).

Table 7

Predictors of birth weight $(n=404)$

\begin{tabular}{llll}
\hline Parameter & $(\%)$ & P-value & Odds ratio $(95 \% \mathrm{CI})$ \\
\hline $\begin{array}{l}\text { Maternal malaria } \\
\text { (14-24 weeks gestation) }\end{array}$ & 45.1 & 0.057 & $1.31(0.92,1.88)$ \\
$\begin{array}{l}\text { Maternal malaria } \\
\text { (28-30 weeks gestation) }\end{array}$ & 26.2 & 0.86 & $1.02(0.79,1.33)$ \\
Maternal malaria delivery & 27 & & \\
Placental malaria & 21.1 & 0.44 & $0.84(0.55,1.30)$ \\
Primigravidae & 21.5 & 0.67 & $1.12(0.67,1.86)$ \\
Height \{162.4 (162.0, 162.8)\} & & 0.24 & $0.1(1.38,18.90)$ \\
Sickle cell trait & 12.7 & 0.25 & $0.41(0.09,1.86)$ \\
Bed net use & 26 & 0.021 & $0.24(0.07,0.80)$ \\
Primigravidae with malaria & & 0.37 & $0.79(0.47,1.32)$ \\
Age (14-46 years) & & 0.47 & $1.03(0.95,1.11)$ \\
\hline
\end{tabular}

The variables considered included gravidity, maternal peripheral parasitaemia at recruitment, at 28-30 weeks gestation and at delivery, placental parasitaemia, age, bed net use and a positive sickling test. Results showed that primigravidity and bed net use were the strongest predictors of birth weight ( $p=0.015$ and $p=0.021$ respectively), while maternal peripheral parasitaemia at enrolment was a weak significant predictor $(\mathrm{P}=0.057)$. The other variables including maternal parasitaemia at 28-30 weeks and at delivery, placental parasitaemia and height had an insignificant effect in the model. The variables entered in the model provided some significant prediction, $\mathrm{X}^{2}(\mathrm{df}=10)=21.685 ; \mathrm{P}=0.017$, with $12.5 \%$ of the variation in birth weights explained by the model (Nagelkerke $R^{2}=0.125$ ).

\section{DISCUSSION}

Weight at birth is not only a good indicator of a mother's health and nutritional status but also the newborn's chances for survival, growth, long term health and psychosocial development. Low birth weight $(<2500 \mathrm{gm})$ carries a range of grave risks for children. Babies who are undernourished in utero face increased risks of dying during their early months of life and those who survive may have impaired physiological functions and increased risk of disease. They are likely to remain undernourished and even suffer increased incidences of metabolic and cardiovascular diseases later in life $(16,21)$.

In our study, the highest number of LBW babies was seen in both the primigravidae and secundigravidae confirming what has been known concerning birth weightand parity $(20,22)$. On malaria infection status, infants born to women with malaria parasitaemia at any time during pregnancy had lower mean birth weights compared to those born to malaria negative women, an indication that malaria is a leading cause of intrauterine growth retardation and LBW as shown in other studies $(23,24)$.

Based on the fact that effective intermittent preventative treatment (IPT) decreases parasitaemia and severe anaemia and improves birth weight especially in primigravidae $(7,14,15,18,25,26)$, we administered two treatment doses of IPT to all study women at $14-24$ weeks and 28 - 30 weeks of gestation respectively. The outcome (although not controlled for all other factors) was an overall $9 \%$ prevalence of LBW in babies born to mothers recruited in the study. This reduction was, however, not significant when compared to the reported $11 \%$ for Bondo District (27) but is an encouragement for the mounting of rigorous programmes aimed at the prevention of LBW babies in malaria endemic communities.

Fourteen point eight percent of LBW infants were found in the primigravidae group. When compared to similar groups of women in other malaria endemic areas of Africa, it is noted that the prevalence of LBW in oursetup was lower than the $40.5 \%$ reported among the primigravidae of the Shire Valley in Malawi, $24.3 \%$ in Suntreso in Ghana, and $31.2 \%$ in Ifakara of Tanzania (27). The observed lower prevalence of LBW as compared to those observed in other areas could be attributed to a number of factors leading to a relatively good antenatal care including the administration of IPT and the combined use of insecticide treated nets which in our study area was at a prevalence of $26 \%$. 
The stage of pregnancy at which malaria infection occurs has also been shown to contribute to birth weight. Our analysis show that women infected with malaria in the first trimester had significantly lowered mean birth weight compared to those who did not have malaria during the same period, an indication that infection in early pregnancy, even if treated, has an effect on the newborn birth weight. This is once more an important finding for the timing of IPT to reduce incidences of low birth weights among pregnant mothers in malaria endemic regions. In addition, the use of bed nets coupled with the administration of IPT reduces the incidences of low birth weight and should therefore be promoted.

Another important factor for low birth weight in this study was maternal haemoglobin concentration. Babies born to women with low $\mathrm{Hb}$ had significantly lower birth weights than those babies born to women with normal Hb levels. Similar findings have been reported in areas of perennial high transmission where malaria in pregnancy is associated with severe maternal anaemia and LBW. Intestinal worms especially hookworm infection at recruitment did not affect birth weight significantly. Women with hookworm infection at recruitmenthad babies with mean birth weight of $45 \mathrm{~g}$ higher than those not infected. This difference was however, not significant. Similar findings have been reported by Luoba et al. working in the same cohort on geophagy and intestinal helminths. They reported that hookworm and trichiuris infection have been associated with higher rather than low haemoglobin concentration. This was attributed to an increase in dietary intake rich in absorbable iron which the women could be accessing.

In conclusion, this study, like many other similar studies, looked at the incidence of low birth weight which occurs primarily as a result of the contribution of a complex of factors playing major roles during pregnancy (30). Such factors are considered as confounders and must be controlled all the times studies of this kind are carried out. IPT for malaria in pregnancy may be a good routine for antenatal care in malaria endemic areas but should be complemented with other malaria control methods including the provision of insecticide treated bed nets. Confounders such as chronic disease, parity status, socioeconomic and nutritional states need to be taken into consideration if efforts to reduce poor pregnancy outcomes are to bear fruits $(31,32)$.

Although efforts were made to control a few of the confounders in our study, it still suffered some limitations since a few of the factors were beyond control. For instance, by the time of the study, HIV seroprevalence in the study area was reported to be as high as $27 \%$ (9) and yet the local population did not approve to HIV testing. As a result, the study did not incorporate HIV testing as a routine antenatal care. It was therefore difficult to assess the impact of HIV on pregnancy outcome in the population. Other factors such as poor socio-economic status, poor nutrition status, the presence of sickle cell trait and disease among many others were, however, considered randomly distributed in the community and hence affecting the outcome of pregnancy uniformly.

\section{ACKNOWLEDGEMENTS}

To the Bondo District community, especially the women who participated in the study. We wish to also thank the District Health Management Team led by the Bondo District Medical Officer of Health for their collaboration. The Provincial Health Team deserves a mention for their support. We also would like to acknowledge Dr. C. Oyoo, (Obstetrician/ Gynaecologist) and Dr. J. Otieno (Paediatrician) for their unwavering support. All the staff in DVBD Kisumu office who participated in the study deserve commendation. Lastly this study was supported by Danida through DBL-Centre for Health Research and Development in Denmark, we are grateful for that support.

\section{REFERENCES}

1. WHO Expert Committee on Malaria. Twentieth Report. WHO Technical Report Series. 2000; 852:3.

2. Mutabingwa, T.K., Geus, deA., Meuwissen,J.H.E.Th. and Malle, L.N. Malaria chemosuppression during pregnancy: Some epidemiological aspects of malaria in infants. Tropical. Geog. 1994; 46: 1-7.

3. Brabin, B. An assessment of low birth weight risk in primiparae as an indicator of malaria control in pregnancy. Intern. J. Epidemiol. 1991; 20: 276-283.

4. McGregor, I.A. Thoughts on malaria in pregnancy with consideration of some factors which influence remedial strategies. Parassitologia. 1987; 29: 153-163.

5. Steketee, R.W., Breman, J.G., Paluku, K.M., et al. Malaria infection in pregnant women in Zaire: the effects and the potential for intervention. Ann. Trop. Med. Parasitol. 1988; 82: 113-120.

6. McDermott, J. M., Heymann, D. L., Wirima, J. I., et al. Efficacy of chemoprophylaxis in preventing Plasmodium falciparum parasitaemia and placental infection in pregnant women in Malawi. Trans. Roy. Soc. Trop. Med. Hyg. 1988; 82: 520-523.

7. Verhooff, F.R., Brabin, B.J., Chimsuku, L., et al. An evaluation of the effects of intermittent sulfadoxinepyrimethamine treatment in pregnancy on parasite clearance and risk of low birth weight in rural Malawi. Ann. Trop. Med. Parasitol. 1998; 92: 141-150.

8. Van den Broek, N.R. and Letzky A.E. Etiology of anaemia in pregnancy in south Malawi. Am. J. Clin. Nutr. 2000; 72: 247S - 256S.

9. Jelliffe, P.F.E. Low birth weight and malarial infection of the placenta. Bull. Wld. Hlth. Org. 1968; 33: 69-78.

10. Guyatt,H.L. andSnow, R.W.Malariain pregnancy as an indirect cause of infant mortality in sub-Saharan Africa. Trans. Roy. Soc. Trop. Med. Hyg. 2001; 95: 569-576. 
11. Luxemburger, C., McGready R., Kham, A., et al. Effects of malaria during pregnancy on infant mortality in an area of low malaria transmission. Am. J. Epidemiol. 2001; 154: 459-465.

12. Schultz, L.J., Steketee, R.W., Macheso, A., et al. The efficacy of antimalarial regimens containing sulfadoxine-pyrimethamine and/or chloroquine in preventing peripheral and placental plasmodium falciparum infection among pregnant women in Malawi. Am. J. Trop. Med. Hyg. 1994; 51: 515-522.

13. Parise, M.E., Ayis, J.G., Nahlen, B.L., et al. Efficacy of sulfadoxine-pyrimethamine for prevention of placental malaria in an area of Kenya with a high prevalence of malaria and human immunodeficiency virus infection. Am. J. Trop. Med. Hyg. 1998; 59: 813822.

14. Wolfe, E.B., Parise, M.E., Haddix, A.C., et al. Costeffectiveness of sulfadoxine-pyrimethamine for the prevention of malaria-associated low birth weight. Am. J. Trop. Med. Hyg. 2001; 64: 178-186.

15. Allen, S.J., Raiko, A., O'Donnell, A., et al. Causes of pre term delivery and intrauterine growth retardation in a malaria endemic region of Papua New Guinea. Archives Dis. Child. Fetal and Neonatal Edition. 1998; 79: F135- F140.

16. Shulman, C.E., Marshall, T., Dorman, E.K., et al. Malaria in pregnancy: adverse effects on haemoglobin levels and birth weight in primigravidae and multigravidae. Trop. Med. Intern. Hlth. 2001; 6: 770778.

17. Greenwood, B.M., Greenwood, A.M., Snow, R.W., et al. The effects of malaria chemoprophylaxis given by traditional birth attendants on the course and outcome of pregnancy. Trans. Roy. Soc. Trop. Med. Hyg. 1989; 83: 589-594.

18. Schultz, L.J., Steketee, R.W., Chitsulo, L. and Wirima, J.J. Antimalarials during pregnancy: a cost effectiveness analysis. Bull. Wld. Hlth. Org. 1995; 73: 207-214.

19. Kramer, M.S. Determinants of low birth weight: methodological assessment and metaanalysis. Bull. Wld. Hlth. Org. 1987; 65: 663-737.

20. McCormick, M.C. The contribution of low birth weight to infant mortality and childhood morbidity. N. Eng. J. Med. 1985; 312: 82-90.
21. Klufio, C.A., Lassy, AT., Annan, B.D and Wilson, J.B. Birth weight distribution at KorleBu Teaching Hospital, Ghana. East. Afr. Med. J. 2001; 78: 418-423.

22. McGregor,I. A, Wilson, M.E and Billewicz, W.Z. Malaria infection of the placenta in The Gambia, West Africa; its incidence and relationship to stillbirth, birthweight and placental weight. Trans. Roy. Soc. Trop. Med. Hyg. 1983; 77: 232-244.

23. Mattelli, A., Caligaris, S. Castelli, F. and Carosi, G. The placenta and malaria. Ann. Trop. Med. Parasitol. 1997: 91: 803-810.

24. Steketee, R.W., Wirima, J.W., Slutsker, L., et al. Malaria parasite infection during pregnancy and at delivery in mother, placenta and newborn: Efficancy of chloroquine and mefloquine in rural Malawi. Am. J. Trop. Med. Hyg. 1996; 55: 24-32.

25. Deen, J.L., von Seidlein, L., Pinder, M., et al. The safety of the combination artesunate and pyrimethaminesulphadoxine given during pregnancy. Trans. Roy. Soc. Trop. Med. Hyg. 2001; 95: 424-428.

26. Kenya Ministry of Health Strategic Plan for Bondo District. MOH 2001.

27. Brabin, B.J., Agbaje, S.O.F., Ahmed, Y. and Briggs, N.D. A birth weight normogram for Africa, as a malariacontrol indicator. Ann. Trop. Med. Parasitol. 1999; 93: S43-S57.

28. Luoba,A.I., Geissler,W.P.,Estambale, B.R.A., etal.Earth - eating and re-infection with intestinal helminths among pregnant and lactating women of western Kenya. Trop. Med. Int. Hlth. 2005; 10: 220 - 227.

29. Bouvier, P., Breslow, N., Doumbo, O., et al. Seasonality, malaria, and impact of prophylaxis in a west African village II. Effect on birth weight. Am. J. Trop. Med. Hyg. 1997; 56: 384-389.

30. Menendez, C., Ordi, J., Ismail, M.R., et al. The impact of placental malaria on gestational age and birth weight. J. Infect. Dis. 2000; 181: 1740-1745.

31. Dreyfuss, M.L., Msamanga, G.I., Spiegelman, D., et al. Determinants of low birth weight among HIVinfected pregnant women in Tanzania. Am. J. Clin. Nutr. 2001; 74: 814-826.

32. HIV / AIDS in Kenya. National AIDS Control Programme (NASCOP), 2001. 